\title{
Clinical response to sunitinib as a multitargeted tyrosine-kinase inhibitor (TKI) in solid cancers: a review of clinical trials
}

This article was published in the following Dove Press journal:

OncoTargets and Therapy

12 May 2014

Number of times this article has been viewed

\section{Sungkyoung Kim \\ Wenping Ding \\ Lian Zhang \\ Wei Tian \\ Siyu Chen}

Department of Oncology, Xin Hua Hospital, Shanghai Jiao Tong University School of Medicine, Shanghai, People's Republic of China
Correspondence: Siyu Chen Department of Oncology, Xin Hua Hospital, Shanghai Jiao Tong University School of Medicine, 1665 Kong Jiang Road, Shanghai 200092, People's Republic of China

Tel +86 2l 25077642

Email siyu.chen@shsmu.edu.cn
Abstract: Angiogenesis is an integral process in carcinogenesis, and molecular inhibitors of angiogenic factors are currently being tested as treatments for cancer. Sunitinib is an oral multitargeted tyrosine-kinase inhibitor that blocks activation through the stem cell-factor receptor (Kit) and platelet-derived growth-factor receptor. Sunitinib has shown potent antitumor activity against several solid tumors, including renal cell carcinoma, gastrointestinal stromal tumors, and neuroendocrine tumors in several Phase II/III trials. Recently, sunitinib has been used to treat other solid cancers, such as lung cancer, pancreatic cancer, chondrosarcoma, esophageal cancer, bladder cancer, glioma, and aggressive fibromatosis, and also showed potential efficacy in progression-free survival and overall survival. In this review, we examine the efficacy of sunitinib as a molecular-targeted therapy in patients with different types of solid cancers.

Keywords: anti-angiogenic therapy, molecular-targeted therapy, tumor, antitumor activity

\section{Introduction}

Sunitinib $\left(\right.$ Sutent ${ }^{\circledR}$; Pfizer, New York, NY, USA) is a multitargeted tyrosine-kinase inhibitor (TKI) with activity against the stem cell-factor receptor (Kit) and plateletderived growth-factor receptor (PDGFR), vascular endothelial growth-factor receptor (VEGFR), glial cell line-derived neurotrophic factor receptor (rearranged during transfection [RET]), colony-stimulating factor-1 receptor (CSF1R), and Fms-like tyrosine kinase-3 receptor (FLT3). ${ }^{1,2}$ Several clinical trials have demonstrated that sunitinib has an objective response rate (ORR) as high as $40 \%$ in the treatment of metastatic renal cell carcinoma ( $\mathrm{mRCC}$ ), and have recommended sunitinib as a first-line therapeutic option. ${ }^{3}$ Another TKI, imatinib, is used in first-line therapy for unresectable and metastatic gastrointestinal stromal tumor (GIST), but in patients who are intolerant to imatinib therapy, sunitinib is recommended as the second-line option in GIST. Results from a Phase I/II study showed that sunitinib had promising clinical activity in patients with imatinib-resistant GIST. ${ }^{4}$ Furthermore, sunitinib has potential antitumor activity in various malignant tumors, such as lung cancer, pancreatic cancer, pancreatic neuroendocrine tumor (PNET), esophageal cancer, bladder cancer, glioma, and sarcoma. ${ }^{5-10}$

This review examines the antitumor efficacy of sunitinib in solid cancers, and summarizes both its preclinical activity and clinical development, including early and latest clinical trials. We discuss the mechanism of sunitinib's antiangiogenic activity and drug-resistance and toxicity studies. We conclude with an examination of the role of sunitinib as a single-agent therapy, combination with chemotherapy or radiotherapy, and its future directions. 


\section{Mechanism of action}

Sunitinib is a multitargeted TKI that acts on VEGFR, PDGFR, Kit, FLT3, RET, and CSF1R, and its antitumor activity has been demonstrated in various tumors. The antioncogenic mechanism of sunitinib is based upon a hypothesis derived from preclinical data of its transition of malignancy to alternative tumor-promoting pathways and its ability to upregulate alternative proangiogenic factors. ${ }^{11}$ Sunitinib is characterized by an oral indolin-2-one structural analog, which inhibits multiple receptor tyrosine kinases (RTKs) and exerts potent antiangiogenesis and antitumor effects. ${ }^{12}$ The spectrum of kinases inhibited by sunitinib includes VEGFR1, -2, and -3, PDGFR $\alpha$, PDGFR $\beta$, Kit, FLT3, RET, and CSF1R. Sunitinib potently and specifically inhibits these targets in biochemical and cell-based assays. ${ }^{13,14}$ Previous studies have shown that sunitinib has the best pharmacologic and binding potency profile for VEGFR and PDGFR at the biochemical and cellular levels. ${ }^{15}$ The phosphorylated receptor acts as a docking domain for intracellular adaptors that lead to the activation of a cascade of intracellular signal-transduction mediators, eventually leading to deoxyribonucleic acid synthesis, cell division, growth, proliferation, and migration. ${ }^{16}$ The Kit TKI sunitinib has shown a promising clinical profile for mastocytosis/mast cell leukemia, germ cell cancers, smallcell lung cancer, GISTs, acute myelogenous leukemia, neuroblastoma, melanoma, ovarian carcinoma, and breast carcinoma. ${ }^{12-17}$ In GIST, sunitinib against wild-type and exon 9-mutant Kit was superior to that of imatinib in vitro, whereas both drugs exhibited similar potency against Kit exon-11 mutant kinases. ${ }^{18} \mathrm{CSF} 1 \mathrm{R}$ is expressed on monocytic progenitors, binds with macrophage CSF to stimulate osteoclasts and enhances the osteolytic activity of osteoclasts. ${ }^{19}$ CSF1R expression has been reported in breast, ovarian, and endometrial cancers, and associated with poor prognosis and invasive potential. Moreover, CSF1R appears to be an attractive target for the treatment of bone metastasis. FLT3 is another TKI that when mutated may lead to the development of a specific type of leukemia, known as acute myeloid leukemia. Furthermore, sunitinib targets mutant RET, which is involved in the multiple endocrine neoplasia types $2 \mathrm{~A}$ and $2 \mathrm{~B}$ autosomal-dominant syndromes, familial medullary thyroid carcinoma, and perhaps sporadic NETs. ${ }^{20}$

\section{Sunitinib in solid cancers}

\section{Single agent as multitargeted TKIs}

Many clinical trials have shown that sunitinib is a first-line therapy for $\mathrm{mRCC}$ and has reasonable ORR, PFS, and OS. ${ }^{20} \mathrm{In}$ a retrospective study of sunitinib for advanced clear-cell RCC ( $\mathrm{n}=76$ ), median PFS was 7.2 months (95\% confidence interval [CI] 4.7-9.7 months) and median OS was 22.8 months (95\% CI 18.7-26.9 months). ${ }^{21}$ The disease-control rate, including complete response (CR), partial response (PR), and stable disease (SD) was $84.2 \%$ (95\% CI 74.0\%-91.6\%). In nonclear-cell RCC ( $\mathrm{n}=10)$, PR was $10 \%$, median PFS was 5.1 months (95\% CI 4.2-6.0 months), and median OS was 9.0 months (95\% CI $0.5-17.4$ months). In another series of retrospective studies conducted by Zama et al, the initial sunitinib treatment $(n=24)$ produced a PR of $65 \%$ and a median PFS of 13.7 months. ${ }^{22}$ Furthermore, a recent study reported that sunitinib was superior to interferon (IFN)- $\alpha$ in PFS and ORR..$^{23}$ A Phase III trial $(n=750)$ measured healthrelated quality of life and compared sunitinib $(n=375)$ with IFN $\alpha(n=375)$ in patients with $\mathrm{mRCC}$, and showed that the health-related quality of life in patients treated with sunitinib was better than patients treated with IFNo. ${ }^{24}$ This means that sunitinib is better in terms of tolerated efficacy and safety than IFN $\alpha$. However, in patients with untreated brain metastases of mRCC, sunitinib cannot be recommended as a valid option, due to its limited efficacy in brain metastases. Notably, no neurologic complication has been observed with sunitinib therapy. ${ }^{25}$ The results of other clinical trials for RCC are summarized in Table 1.

The effective systemic therapy for GIST is imatinib and sunitinib, routinely. ${ }^{33,34}$ As the first-line systemic treatment in patients with metastatic GIST, imatinib induces regression or stabilization in over $80 \%$ of patients, and sunitinib can achieve responses in patients refractory to imatinib. 35,36 A retrospective study conducted to evaluate the effect of sunitinib in GIST patients showed that sunitinib had a clinical benefit (including CR, PR, and SD) of $65.2 \%$ after 6 months of administration. ${ }^{17}$ Table 2 shows the clinical efficacy of sunitinib for treatment in patients with refractory GIST or who are intolerant to imatinib.

Single-agent sunitinib has also demonstrated antitumor activity in several preclinical breast cancer models, both alone and in combination with chemotherapy. ${ }^{39}$ A Phase II trial demonstrated that patients with refractory, late-stage metastatic breast cancer receiving sunitinib as monotherapy had PR of $11 \%$ and SD of $5 \%{ }^{40}$ The median time to progression (TTP) and OS were 10 and 38 weeks, respectively, in this study. However, the efficacy of sunitinib monotherapy was inferior to standard care with chemotherapy in advanced triple-negative breast cancer that lacks expression of the estrogen receptor, progesterone receptor and human epidermal growth-factor receptor 2 (Table 3). ${ }^{41}$ 
Table I Clinical trials of SU (25-50 mg/day, orally, days I-I4, every 21 days) as a single agent in mRCC (20I0-20I3)

\begin{tabular}{|c|c|c|c|c|c|c|c|c|c|}
\hline \multirow[t]{2}{*}{ Study } & \multirow[t]{2}{*}{ Phase } & \multirow[t]{2}{*}{ Patients } & \multirow[t]{2}{*}{ Therapy } & \multicolumn{6}{|c|}{ Results (RECIST) } \\
\hline & & & & $\begin{array}{l}\text { mORR (\%) } \\
\text { (CR or PR) }\end{array}$ & $\begin{array}{l}\text { mSD } \\
(\%)\end{array}$ & $\begin{array}{l}\text { mPD } \\
(\%)\end{array}$ & $\begin{array}{l}\text { mTTP } \\
\text { (months) }\end{array}$ & $\begin{array}{l}\text { mPFS } \\
\text { (months) }\end{array}$ & $\begin{array}{l}\text { mOS } \\
\text { (months) }\end{array}$ \\
\hline \multirow[t]{2}{*}{ Zama et a $\left.\right|^{22}$} & I & 23 & Initial SU & 65 (PR) & 29 & 4 & - & 13.7 & - \\
\hline & & 23 & Rechallenge & 21 (PR) & 71 & 8 & - & 7.2 & - \\
\hline \multirow[t]{2}{*}{ Keizman et $\mathrm{a}^{26}$} & 1 & 44 & SU & $86(P R+S D)$ & & 14 & - & 13 & 30 \\
\hline & & 83 & Nonusers & $72(P R+S D)$ & & 28 & - & 6 & 23 \\
\hline \multirow[t]{3}{*}{ Molina et $\mathrm{al}^{27}$} & ॥ & 23 & All & $4(\mathrm{PR})$ & 65 & 26 & - & 5.5 & - \\
\hline & & 8 & Papillary & 0 & 26 & 8.6 & - & - & - \\
\hline & & 15 & Non-clear cell & 4 (PR) & 39 & 17.4 & - & - & - \\
\hline \multirow[t]{4}{*}{ Rini et $\mathrm{al}^{28, \#}$} & III & 442 & $\mathrm{SBP}: \geq 140 \mathrm{mmHg}$ & $54.8(\mathrm{CR}+\mathrm{PR})$ & - & - & - & 12.5 & 30.9 \\
\hline & & 92 & $<140 \mathrm{mmHg}$ & $8.7(\mathrm{CR}+\mathrm{PR})$ & - & - & - & 2.5 & 7.2 \\
\hline & & 363 & DBP: $\geq 90 \mathrm{mmHg}$ & $57.3(\mathrm{CR}+\mathrm{PR})$ & - & - & - & 13.4 & 32.2 \\
\hline & & |7| & $<90 \mathrm{mmHg}$ & $24.6(\mathrm{CR}+\mathrm{PR})$ & - & - & - & 5.3 & 14.9 \\
\hline van der & I & 55 & RECIST & I3 (PR) & 69 & 18 & - & 11.2 & 13.2 \\
\hline Veldt et $\mathrm{a}^{29}$ & & 55 & Choi criteria $^{2}$ & 65 (PR) & 11 & 24 & - & 16.1 & 20 \\
\hline Yoo et $\mathrm{al}^{30}$ & 1 & 65 & SU & 43 (PR) & 43 & 8 & 11.8 & - & 22.8 \\
\hline Molina et $\mathrm{a}^{31}$ & I & 20 & SU + everolimus* & $25(\mathrm{PR})$ & 62.5 & 6 & - & 8.7 & - \\
\hline \multirow[t]{2}{*}{ Keizman et $\mathrm{al}^{32}$} & 1 & 35 & SU + bisphosphonates & $86(P R+S D)$ & & 14 & - & 15 & - \\
\hline & & 41 & SU + nonbisphosphonate & $71(P R+S D)$ & & 29 & - & 5 & 14 \\
\hline
\end{tabular}

Notes: "Sunitinib-induced hypertension with antitumor efficacy; *everolimus 2.5-5 mg daily or 20-30 mg weekly.

Abbreviations: $\mathrm{mRCC}$, metastatic renal cell carcinoma; mORR, median objective response rate; PR, partial response; CR, complete response; mSD, median stable disease; mPD, median progressive disease; mTTP, median time to progression; mPFS, median progression-free survival; mOS, median overall survival; mRCC, metastatic renal cell carcinoma; RECIST, Response Evaluation Criteria in Solid Tumors; SU, sunitinib; SBP, systolic blood pressure; DBP, diastolic blood pressure.

A Phase II study showed the limited efficacy of sunitinib in patients with advanced esophageal cancer, and over half of patients discontinued due to disease progress and toxicity. ${ }^{42}$ In patients with aggressive fibromatosis, sunitinib showed potential antitumor activity and was relatively well tolerated. ${ }^{43}$ In previous clinical trials for advanced hepatocellular carcinoma (HCC), sunitinib failed its primary OS end point, but PFS and TTP results were similar between sunitinib and sorafenib. ${ }^{44}$ Sunitinib was associated with more frequent toxicities versus sorafenib. After sorafenib-treatment failure in advanced hepatocellular carcinoma, sunitinib had substantial antitumor activity with a manageable toxicity profile..$^{45}$

Several Phase II trials have shown limited efficacy of PR and SD in metastatic thyroid cancer. ${ }^{46}$ A retrospective study showed that PR was obtained in $55.5 \%$ of patients, median PFS and OS were 21 and 21 months, respectively, and confirmed that sunitinib is a potential useful option for the treatment advanced thyroid cancer. ${ }^{47}$ In another Phase II study, sunitinib was administered daily on a continuous basis, and there was $3 \% \mathrm{CR}, 28 \% \mathrm{PR}$, and $46 \%$ with SD. PD was observed at $17 \%$, and median TTP was 12.8 months. ${ }^{48}$

Table 2 Clinical studies of SU (25-50 mg/day, orally, days I-I4, every 2 I days) as a single agent in GIST (20I0-20I3)

\begin{tabular}{|c|c|c|c|c|c|c|c|c|c|}
\hline \multirow[t]{2}{*}{ Study } & \multirow[t]{2}{*}{ Phase } & \multirow[t]{2}{*}{ Patients } & \multirow[t]{2}{*}{ Therapy } & \multicolumn{6}{|c|}{ Results (RECIST) } \\
\hline & & & & $\begin{array}{l}\text { mORR }(\%) \\
\text { (CR or PR) }\end{array}$ & $\begin{array}{l}\mathrm{mSD} \\
(\%)\end{array}$ & $\begin{array}{l}\mathrm{mPD} \\
(\%)\end{array}$ & $\begin{array}{l}\text { mTTP } \\
\text { (months) }\end{array}$ & $\begin{array}{l}\text { mPFS } \\
\text { (months) }\end{array}$ & $\begin{array}{l}\text { mOS } \\
\text { (months) }\end{array}$ \\
\hline \multirow[t]{2}{*}{ Younus et $\mathrm{al}^{4}$} & III & 207 & SU & $7(C R+P R)$ & 17.4 & - & 27.3 & 24.1 & - \\
\hline & & 105 & Placebo & $0(\mathrm{CR}+\mathrm{PR})$ & 1.9 & - & 6.4 & 6.0 & - \\
\hline Rutkowski et al ${ }^{9}$ & 1 & 137 & SU & $15(P R)$ & 45 & 37 & - & 10.7 & 18.3 \\
\hline Chen et $\mathrm{al}^{17}$ & I & 23 & SU & $26.1(C R+P R)$ & 39.1 & 34.8 & - & 8.4 & 14.1 \\
\hline Italiano et $\mathrm{a}^{36}$ & 1 & 223 & SU & - & - & - & - & 9.5 & - \\
\hline \multirow[t]{3}{*}{ Bertucci et $\mathrm{al}^{37, *}$} & III & 58 & After I year & - & - & - & - & 7 & - \\
\hline & & 50 & After 3 years & - & - & - & - & 9 & - \\
\hline & & 27 & After 5 years of imatinib & - & - & - & - & 13 & - \\
\hline Matsumoto et $\mathrm{a}^{38}$ & II & 80 & SU & $5.6(\mathrm{PR})$ & 38.9 & 44.4 & - & - & - \\
\hline
\end{tabular}

Note: *Randomized in imatinib-refractory.

Abbreviations: GIST, gastrointestinal stromal tumor; mORR, median objective response rate; CR, complete response; PR, partial response; $m S D$, median stable disease; mPD, median progressive disease; mTTP, median time to progression; mPFS, median progression-free survival; mOS, median overall survival; RECIST, Response Evaluation Criteria in Solid Tumors; SU, sunitinib. 
Table 3 Current clinical trials of SU (25-50 mg/day, orally, days I-I4, every 2 I days) for solid cancers (20II-20I3)

\begin{tabular}{|c|c|c|c|c|c|c|c|c|c|}
\hline \multirow[t]{2}{*}{ Disease } & \multirow[t]{2}{*}{ Study (Phase) } & \multirow[t]{2}{*}{ Patients } & \multirow[t]{2}{*}{ Therapy } & \multicolumn{6}{|c|}{ Results (RECIST) } \\
\hline & & & & $\begin{array}{l}\text { mORR (\%) } \\
\text { (CR or PR) }\end{array}$ & $\begin{array}{l}\text { mSD } \\
(\%)\end{array}$ & $\begin{array}{l}\text { mPD } \\
(\%)\end{array}$ & $\begin{array}{l}\text { mTTP } \\
\text { (months) }\end{array}$ & $\begin{array}{l}\text { mPFS } \\
\text { (months) }\end{array}$ & $\begin{array}{l}\text { mOS } \\
\text { (months) }\end{array}$ \\
\hline \multicolumn{10}{|c|}{ Single agent } \\
\hline \multirow[t]{2}{*}{$A B C$} & Curigliano et al ${ }^{41}$ (II) & 113 & SU & $3(C R+P R)$ & - & - & - & 2.0 & 9.4 \\
\hline & & 104 & $\begin{array}{l}\text { Standard of care } \\
\text { with chemotherapy }\end{array}$ & $7(C R+P R)$ & - & - & - & 2.7 & 10.5 \\
\hline AEC & Knox et al ${ }^{42}$ (II) & 70 & As adjuvant therapy & - & - & 52 & - & - & $24(50 \%)$ \\
\hline $\mathrm{AF}$ & Jo et $\mathrm{a}^{43}$ (II) & 19 & SU & $26.3(\mathrm{PR})$ & 42.1 & - & - & $24(74 \%)$ & $24(94 \%)$ \\
\hline \multirow[t]{2}{*}{$\mathrm{AHC}$} & Cheng et al ${ }^{44}$ (III) & 529 & SU 400 mg/day, & - & - & - & 4.1 & 3.6 & 8.1 \\
\hline & & 544 & twice a day & - & - & - & 4.0 & 2.9 & 10 \\
\hline $\mathrm{MHC}^{\mathrm{a}}$ & Yau et $\mathrm{al}^{45}$ (II) & 38 & SU & $6(P R)$ & 34 & - & 2.9 & - & 5.2 \\
\hline MTC & Pasqualetti et $\mathrm{al}^{47}(\mathrm{I})$ & 9 & SU & $55.5(\mathrm{PR})$ & - & - & - & 21 & 21 \\
\hline \multirow[t]{2}{*}{ MUM } & Sacco et $\mathrm{a}^{50}$ (II) & 74 & SU & 0 (PR) & 24 & - & - & 2.7 & 6.3 \\
\hline & & & Dacarbazine $^{\mathrm{b}}$ & 8 (PR) & 11 & - & - & 3.8 & 8.6 \\
\hline \multirow[t]{4}{*}{ NSCLC } & Reynolds et al ${ }^{51}$ (II) & 63 & SU & $6.7(\mathrm{CR}+\mathrm{PR})$ & 56.7 & 15 & 4.5 & 3 & 5.8 \\
\hline & Heist et $\mathrm{a}^{52}$ (II) & 41 & SU & - & - & - & - & 3.3 & 7.0 \\
\hline & & 41 & Pemetrexed + SU & - & - & - & - & 3.7 & 6.7 \\
\hline & & 46 & Pemetrexed & - & - & - & - & 4.4 & 10.5 \\
\hline SCLC & Han et $\mathrm{a}^{53}$ (II) & 25 & SU & $9(\mathrm{CR}+\mathrm{PR})$ & 30 & - & - & 1.4 & 5.6 \\
\hline \multirow[t]{2}{*}{ PNET } & Raymond et al ${ }^{54}$ (III) & 86 & SU & - & - & - & - & 12.6 & 30.5 \\
\hline & & 85 & Placebo & - & - & - & - & 5.8 & 24.4 \\
\hline \multicolumn{10}{|c|}{ Combination with chemotherapy } \\
\hline \multirow[t]{2}{*}{ AGC } & Lee et $\mathrm{a}^{57}(\mathrm{I})$ & 28 & $\mathrm{SU}+\mathrm{XPc}$ & $46.7(C R+P R)$ & & & & & 6.4 \\
\hline & & 48 & $S U+X E L O X^{d}$ & $45.5(C R+P R)$ & & & & & 8.0 \\
\hline \multirow[t]{2}{*}{$A B C$} & Robert et $\mathrm{al}^{58}$ (III) & 242 & SU + paclitaxel & 78 & - & - & - & 7.4 & 17.6 \\
\hline & & 243 & Bevacizumab + paclitaxel & 78 & - & - & - & 9.2 & - \\
\hline \multirow[t]{3}{*}{ AEC } & Moehler et a $\left.\right|^{59}$ (II) & 45 & FOLFIRI ${ }^{g}+\mathrm{SU}$ & $20(C R+P R)$ & - & - & - & 3.6 & 10.5 \\
\hline & & 46 & FOLFIRI + placebo & $29(\mathrm{CR}+\mathrm{PR})$ & - & - & - & 3.3 & 9 \\
\hline & Schmitt et a $\left.\right|^{60}$ (II) & 28 & SU + paclitaxel & II (CR + PR) & - & - & - & $24(25 \%)$ & 8.1 \\
\hline \multirow[t]{2}{*}{ APC } & Richly et al|l| (II) & 113 & Gemcitabine + SU & $7 . I(\mathrm{ORR}+\mathrm{SD})$ & & - & 4.5 & 2.9 & 7.6 \\
\hline & & & Gemcitabine $^{e}$ & $6.1(\mathrm{ORR}+\mathrm{SD})$ & & - & 3.5 & 3.3 & 9.1 \\
\hline Glioma $^{f}$ & Duerinck et $\mathrm{a}^{63}$ (II) & 13 & $\begin{array}{l}\mathrm{SU}+\text { lomustine } \\
\text { (lomustine } 80 \mathrm{mg} / \mathrm{m}^{2} \text { ) }\end{array}$ & $15(\mathrm{CR}+\mathrm{PR})$ & 15 & - & 15.2 & 1.8 & - \\
\hline \multirow[t]{2}{*}{ MPM } & Laurie et $\mathrm{al}^{64}$ (II) & 17 & Prechemotherapy & $0(C R+P R)$ & 64.7 & - & - & 2.8 & 8.3 \\
\hline & & 18 & Previously untreated & $5.5(\mathrm{CR}+\mathrm{PR})$ & 55.5 & - & - & 2.7 & 6.7 \\
\hline MUC & Galsky et al ${ }^{65}(\mathrm{l})$ & 36 & SU + gemcitabine + cisplatin & $49(\mathrm{CR}+\mathrm{PR})$ & 15 & - & - & 8 & 13.8 \\
\hline \multirow[t]{2}{*}{ SCLC } & Ready et $\mathrm{a}^{66}$ (II) & 44 & Chemotherapy + SU & - & - & - & - & 3.8 & 8.8 \\
\hline & & 41 & Chemotherapy + placebo & - & - & - & - & 2.3 & 6.7 \\
\hline
\end{tabular}

Notes: aMHC after sorafenib failure; bdacarbazine I,000 mg/m² every $2 \mathrm{I}$ days; ${ }^{\mathrm{c}}$ capecitabine + cisplatin (XP); ${ }^{\mathrm{d}}$ capecitabine + oxaliplatin (XELOX); ${ }^{\mathrm{e}}$ gemcitabine I,000 mg/ ${ }^{2}$ days I, 8, 15 every 28 days; 'glioma temozolomide-refractory; 85 -fluorouracil+irinotecan+leucovorin (FOLFIRI).

Abbreviations: ABC, advanced breast cancer; AGC, advanced gastric cancer; AEC, advanced esophageal cancer; AF, aggressive fibromatosis; AHC, advanced hepatocellular carcinoma; APC, advanced pancreatic cancer; MHC, metastatic hepatocellular carcinoma; MIBC, muscle-invasive bladder cancer; MPM, malignant pleural mesothelioma; MTC, metastatic thyroid cancer; MUC, metastatic urothelial carcinoma; MUM, metastatic uveal melanoma; NSCLC, non-small-cell lung cancer; PNET, pancreatic neuroendocrine tumor; SCLC, small-cell lung cancer; mORR, median objective response rate; CR, complete response; PR, partial response; mSD, median stable disease; mPD, median progressive disease; mTTP, median time to progression; mPFS, median progression-free survival; mOS, median overall survival; RECIST, Response Evaluation Criteria in Solid Tumors; SU, sunitinib.

However, sunitinib, as first-line therapy in metastatic uveal melanoma, did not have significant clinical activity. ${ }^{49,50}$

In randomized Phase II trials, sunitinib for the treatment of non-small-cell lung cancer (NSCLC) showed acceptable disease-control response and quality of life improved. ${ }^{51}$ However, most patients with SCLC were unable to tolerate the treatment of sunitinib with short PFS (Table 3). ${ }^{53}$

A study suggested that sunitinib on a continuous daily dosing schedule showed anti-tumor activity in patients with unresectable, well-differentiated PNET. ${ }^{5}$ A Phase II study showed that the clinical benefit rate was $75 \%$, ORR was $50 \%$, and PFS was $91 \%$ at 6 months and $71 \%$ at 12 months. ${ }^{10}$ Raymond et al reported that single-agent sunitinib had a 12.6-month median PFS. ${ }^{54}$ In an early study, sunitinib significantly reduced the growth of castration-resistant prostate cancer and decreased prostate-specific antigen levels. ${ }^{55}$ A Phase I/II trial in metastatic castration-resistant prostate cancer demonstrated that nine of 18 patients exhibited 
prostate-specific antigen responses of $\geq 50 \%$, and five of 13 manifested partial radiographic responses. Moreover, in patients with docetaxel-resistant metastatic prostate cancer, sunitinib showed a 12 -week PFS of $79 \% .^{56}$

\section{Sunitinib combined with chemotherapy}

Many Phase I/II studies of sunitinib in combination with chemotherapy have shown activity and manageable toxicities. However, some Phase III studies have been terminated prematurely or halted due to futility. ${ }^{40,46}$ In advanced gastric cancer, a Phase I study showed that sunitinib combined with capecitabine/oxaliplatin had an acceptable safety profile over sunitinib combined with capecitabine/cisplatin. ${ }^{57}$ However, in advanced breast cancer, the sunitinib-paclitaxel regimen was clinically inferior to the bevacizumab-paclitaxel regimen. ${ }^{58}$ The addition of sunitinib to chemotherapy has yet to demonstrate a significant PFS or OS advantage in patients with advanced esophageal cancer. Comparison of treatment with the FOLFIRI (irinotecan, leucovorin, and fluorouracil) regimen plus sunitinib versus FOLFIRI alone in patients with advanced chemotherapy-refractory esophagogastric cancer, showed that sunitinib added to FOLFIRI increased hematotoxicity and did not improve ORR or PFS in chemotherapy-resistant patients. ${ }^{59}$

In advanced pancreatic cancer, the combination of gemcitabine plus sunitinib did not improve PFS compared to gemcitabine alone. ${ }^{61}$ Phase I/II studies on sunitinib treatment in recurrent malignant glioma have shown that the combination of sunitinib and lomustine or irinotecan has limited antitumor activity and acceptable toxicity. ${ }^{62,63}$ Sunitinib also has limited activity in malignant pleural mesothelioma, and the response rate was superior to previously cisplatin-based treated patient. ${ }^{64}$ The efficacy of sunitinib in patients with relapsed or refractory lung cancer is shown in Table 3. In NSCLC, sunitinib had an inferior toxicity profile to pemetrexed, and OS was significantly better with pemetrexed alone compared to sunitinib-containing arms, with pemetrexed plus sunitinib performing worse for OS. ${ }^{52}$ Sunitinib administration after chemotherapy for extensive-stage SCLC improved PFS, but there was no significant trend toward improved OS. ${ }^{6}$

\section{Sunitinib combined with radiotherapy}

In chondrosarcoma, sunitinib is beneficial, and may be safely combined with proton-beam radiation therapy. ${ }^{67}$ Sunitinib concurrent with stereotactic radiation resulted $\mathrm{CR}$ and PR of $42 \%$ and $17 \%$, respectively, and $28 \%$ patients had SD. A Phase I/II trial was conducted by Kao et al, ${ }^{68}$ in which
46 patients with oligometastases, defined as five or fewer clinical detectable metastases from any primary site, were treated with $37.5 \mathrm{mg}$ sunitinib (days 1-28) and stereotactic body-radiation therapy of 50 Gy (days 8-12 and 15-19). Local control and distant control were $75 \%$ and $40 \%$, and PFS and OS 34\% and 29\%, respectively. This study supported the belief that patients with kidney and prostate primary tumors are associated with significantly improved OS.

\section{Challenges for several cancers}

The question of whether sunitinib-induced apoptosis is associated with the induction of Bim or downregulation of Mcl-1 in some colon cancer cell lines has been tested. In addition, a recent study demonstrated that sunitinib induces the p53upregulated modulator of apoptosis (PUMA), which plays an essential role in p53-dependent and -independent apoptosis in human cancer cells and mice, but its expression is independent of p53 in colon cancer cells. Moreover, a number of more selective VEGFR inhibitors were also found to induce PUMA and apoptosis in colon cancer cells, supporting the non-angiogenic role of anti-VEGFR therapies. ${ }^{69,70}$

The number of circulating endothelial cells may be useful to predict benefit from maintenance sunitinib therapy. A Phase II study of sunitinib in high-risk patients with uveal melanoma is ongoing, and preliminary data have shown that PFS and OS rates at 2 years were $70 \%$ and $100 \%$, respectively. ${ }^{50} \mathrm{~A}$ randomized Phase II study evaluated the efficacy of sunitinib versus dacarbazine in the treatment of patients with metastatic uveal melanoma. ${ }^{71} \mathrm{~A}$ Phase II trial of sunitinib in metastatic non-clear RCC is ongoing to evaluate the efficacy of sunitinib compared with everolimus. ${ }^{72}$

\section{Resistance of sunitinib}

The development of sunitinib resistance is accompanied by evasion of antiangiogenic effects and by increased expression of tumor-derived interleukin (IL)-8. ${ }^{73}$ IL-8 expression was elevated in human RCC tumors with intrinsic resistance to sunitinib therapy, indicating that IL-8 levels may serve as a predictive biomarker for clinical response to sunitinib. ${ }^{74}$ Obviously, IL-8 plays an important role in the resistance of RCC to sunitinib, and suggests that IL-8 may potentially serve as both a therapeutic target for the treatment of sunitinib-resistant RCC and as a clinical biomarker for both acquired and intrinsic sunitinib resistance. The best marker gene, $A M F R$, is highly downregulated in sunitinib-sensitive patients. The $A M F R$ gene is associated with angiogenesis and tumor cell motility, and its identification may improve outcome prediction and improve our understanding of the mechanisms of 
resistance. ${ }^{75}$ Furthermore, Sato et al reported that the extracellular matrix metalloproteinase inducer (EMMPRIN) plays an important role in tumor progression and sunitinib resistance in RCC. ${ }^{76}$ EMMPRIN is highly expressed in human RCC cells, and it plays an important role in their angiogenesis and aggressiveness both in vitro and in vivo. Further studies are required to confirm that targeting EMMPRIN in RCC inhibits tumor angiogenesis, progression, and resistance to TKIs and mammalian target-of-rapamycin inhibitors.

\section{Toxicity of sunitinib}

A recent study suggested that grade 3-4 clinical TKI-related toxicities, namely digestive, cardiac, dermatologic, and asthenia, are associated with a significant improvement of OS. ${ }^{77}$ Several studies reported that the occurrence of overall grade 3-4 toxicities was significantly associated with age, body surface, and sex. Another study reported that the most common toxicities experienced at both initial treatment and rechallenge were fatigue, diarrhea, and hand-foot syndrome. ${ }^{78}$ A retrospective study showed that stomatitis $(63.2 \%)$ and diarrhea $(60.5 \%)$ were the most commonly reported dose-related adverse events. ${ }^{79}$ In $\mathrm{mRCC}(\mathrm{n}=132)$, the most common adverse events were stomatitis $(66.7 \%)$, fatigue $(52.3 \%)$, hand-foot syndrome (49.2\%), and anorexia (48.5\%). ${ }^{80}$ Moreover, the most frequent laboratory abnormality was thrombocytopenia ( $75 \%$ ), and $37.8 \%$ of patients experienced grade 3 or 4 thrombocytopenia. Other common laboratory abnormalities included increased serum creatinine (75.6\%) and elevated alanine aminotransferase $(53.5 \%)$. Chen et al reported that sunitinib-induced hypothyroidism was observed as a side effect in $12 \%$ of GIST patients. ${ }^{17}$ The molecular mechanisms of sunitinib-induced hypothyroidism are currently unknown, but one possible mechanism may be via inhibition of VEGFR and/ or PDGFR in the thyroid tissue. ${ }^{81}$

\section{Discussion}

Since it is a multitargeted TKI, sunitinib's main mechanism of action is through inhibition of tumor angiogenesis, but it also has antiproliferative and apoptotic effects on diverse tumor types. ${ }^{82}$ Sunitinib exerts its activity as a competitive inhibitor of the catalytic activity of a group of strictly related RTKs: VEGFR1, -2 , and -3, PDGFR- $\alpha$ and $-\beta$, Kit, CSF1R, FLT3, and the RTK encoded by the RET proto-oncogene. ${ }^{83}$ Sunitinib exerts potent and specific inhibition of these targets in biochemical and cell-based assays. ${ }^{84}$ In vitro, sunitinib inhibited VEGF-dependent proliferation and migration of human umbilical endothelial cells and disrupted capillary tube formation, and in in vivo models of cancer angiogenesis, sunitinib decreased tumor-microvessel density, blocked vascularization in the vascular window tumor model, and decreased the metastatic potential of several cancers, such as Lewis lung cancer. ${ }^{85,86}$ Sunitinib inhibited the proliferation of human cancer cells induced by VEGF, Kit, and PDGF, while inducing apoptosis in human umbilical endothelial cells in an in vitro study. ${ }^{87}$ Preclinical studies suggest that plasma concentrations in the range of 50-100 ng/mL inhibited target activation. ${ }^{88}$ In in vivo studies, sunitinib exerted significant antitumor activity in xenograft models from numerous tumor types, including renal, colon, breast, lung, melanoma, and epidermoid carcinoma, with once-daily dosing. ${ }^{89}$

We summarized the clinical response of sunitinib, as shown in Tables 1-3. Sunitinib was generally established as a first-line therapy in advanced RCC and second-line therapy in GISTs after disease progression or intolerance to imatinib therapy. Recent clinical trials have reported that sunitinib has strong anticancer activity in PNET and has potential response in other cancers, since VEGF levels are highly correlated with the clinical output of well-vascularized tumors. Clinical trials have shown that sunitinib can be administrated as a single agent or in combination with chemotherapy or radiotherapy in different types of advanced cancers. Most clinical trials have suggested that sunitinib is efficacious, especially in $\mathrm{mRCC}$ and GIST, as a single agent. The benefits of sunitinib have also been shown in SCLC, NSCLC, and advanced esophageal cancer, and in combination therapy in urinary cancer. ${ }^{83-88}$ Much of our experience with sunitinib has been with the maximum tolerated dose of $75 \mathrm{mg}$ and the recommended dose of $50 \mathrm{mg} /$ day, 4 weeks on, 2 weeks off schedule in solid cancers.

Our review has demonstrated that sunitinib has a significant, beneficial response in $\mathrm{mRCC}$ and GIST. A beneficial response has also been shown in SCLC, breast cancer, thyroid cancer, chondrosarcoma, and other cancers. There are different responses in different types of cancers (Figure 1), and previous studies have supported the belief that relative factors may be associated with the clinical response. These studies have suggested some predictive biomarkers, such as an increase in circulating endothelial cells and smoking, but body mass index, diabetes mellitus, and pretherapy hypertension were not found to be associated with outcome. ${ }^{28}$ It is apparent that there needs to be a definition of the optimal biologic dose of antiangiogenic agents used as treatment for mRCC, GIST, and PNET. The combination of sunitinib and chemotherapy can improve OS in several solid cancers, such as SCLC and advanced esophageal cancer. However, sunitinib has failed as a treatment for NSCLC, metastatic breast cancer, and advanced pancreatic cancer. Although many trials have suggested that 

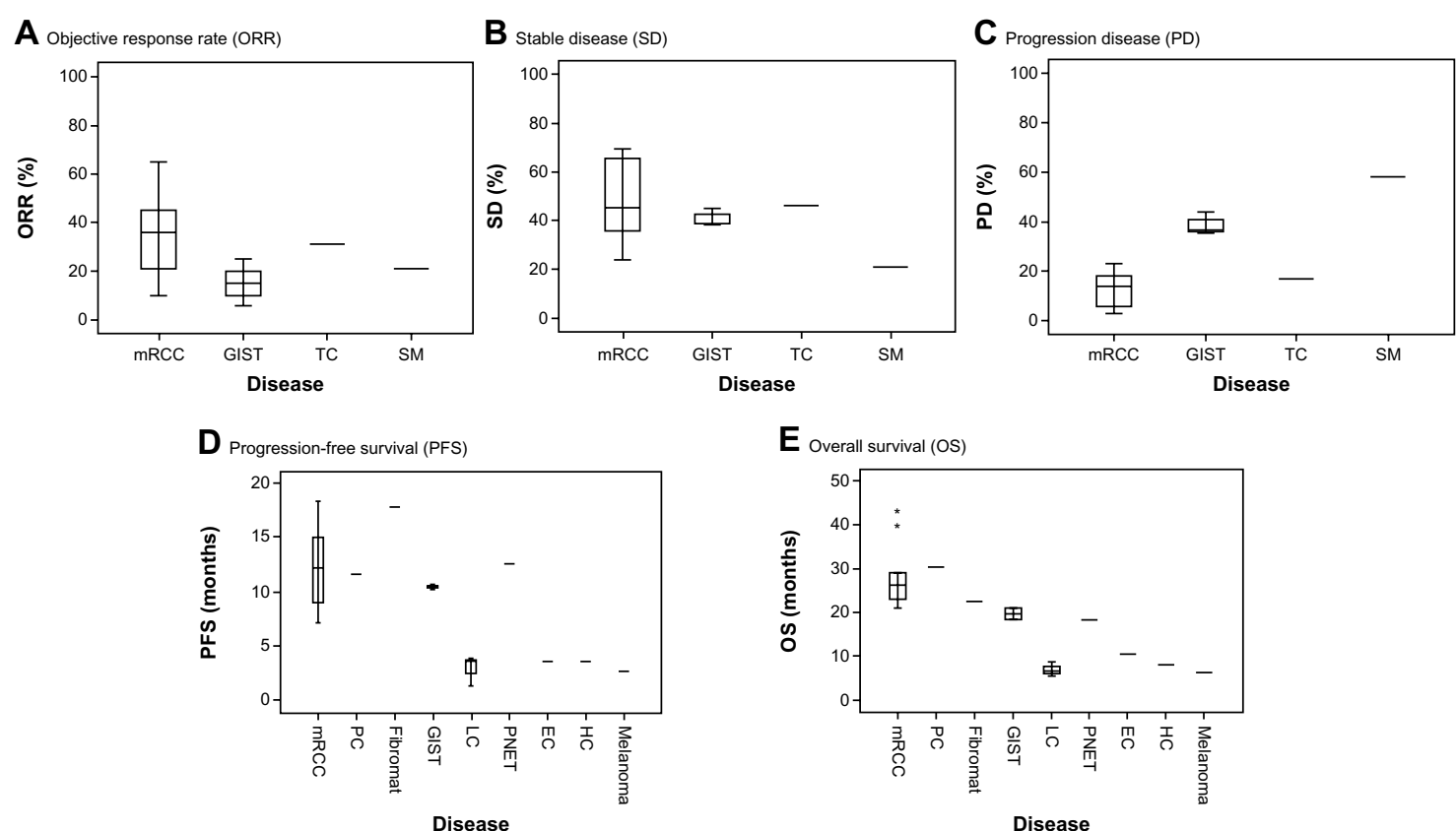

Figure I (A-E) Clinical response to sunitinib in solid cancers (20I0-2013). A summary of study reviews, including early and late clinical trials (Phase I-III studies). (A-C) mRCC and GIST, 18 and six clinical studies, respectively; TC and SM, one clinical study each. (D-E) mRCC, 18 clinical studies; GIST, six studies; PNET, EC, and HC, two studies each; PC, fibromatosis, and melanoma, one clinical study each.

Note: *Maximum values.

Abbreviations: mRCC, metastatic renal cell cancer, peroral treatment; PC, pancreatic cancer (combined with gemcitabine); GIST, gastrointestinal stromal tumor (secondline after imatinib resistance); LC, lung cancer (involving non-small-cell lung cancer and small-cell lung cancer, combined with chemotherapy); EC, esophageal cancer (advanced, combined with chemotherapy); HC, hepatocellular cancer (advanced, after sorafenib-refractory); Fibromat, aggressive fibromatosis; melanoma, metastatic uveal melanoma; SM, solid malignancy; TC, thyroid cancer; PNET, pancreatic neuroendocrine tumor.

sunitinib represents a major therapeutic advancement in the treatment of $\mathrm{mRCC}$, the best response to multikinase inhibitors is only temporary disease stabilization. For this purpose, a Phase II study was conducted to evaluate the efficacy of erlotinib (150 mg/day, orally) and sirolimus (6 mg orally on day 8 , followed by $2 \mathrm{mg}$ daily) in $\mathrm{mRCC}$ patients after failure with sunitinib or sorafenib $(n=25) .{ }^{90}$ The results showed that median PFS for these patients was 12 weeks (95\% CI 5.9-18.1) and median OS 40 weeks (95\% CI 0-85.7). SD of less than 6 months was noted in $21.8 \%$ (95\% CI 4.9\%-38.6\%) of patients. No confirmed CR or PR was observed.

\section{Conclusion}

For now, further developmental and investigational studies are necessary to demonstrate the mechanism of drug-resistance, to aid in the development of advanced clinical trials, and to design more effective monoclonal antibodies for the treatment of sunitinib-refractory cancers.

\section{Acknowledgments}

This work was supported by the National Natural Science Foundation of China (81274142), the Natural Science Foundation of Science and Technology Commission of
Shanghai Municipality (11ZR1423400), and the Key Project of Shanghai Municipal Education Commission (07zz43).

\section{Disclosure}

The authors declare no conflicts of interest in this work.

\section{References}

1. Sweeney CJ, Chiorean EG, Verschraegen CF, et al. A phase I study of sunitinib plus capecitabine in patients with advanced solid tumors. J Clin Oncol. 2010;28(29):4513-4520.

2. Yoon SH, Kim KH, Choi J, et al. Novel sunitinib strategy in metastatic renal cell carcinoma on hemodialysis: intermittent dose of sunitinib after hemodialysis. Cancer Res Treat. 2010;42(3):180-184.

3. Li XS, Wu X, Zhao PJ, et al. Efficacy and safety of sunitinib in the treatment of metastatic renal cell carcinoma. Chin Med J (Engl). 2011;124(18):2920-2924.

4. Younus J, Verma S, Franek J, Coakley N; Sacroma Disease Site Group of Cancer Care Ontario's Program in Evidence-Based Care. Sunitinib malate for gastrointestinal stromal tumour in imatinib mesylate-resistant patients: recommendations and evidence. Curr Oncol. 2010;17(4):4-10.

5. Granberg D, de Herder W, O'Toole D, Kvols L. Treatment of liver metastases in patients with neuroendocrine tumors. Int $J$ Hepatol. 2012;2012:790635.

6. Coppin C. Sunitinib for advanced renal cell cancer. Biologics. 2008; 2(1):97-105.

7. Heyerdahl H, Abbas N, Brevik EM, Mollatt C, Dahle J. Fractionated therapy of HER2-expressing breast and ovarian cancer xenografts in mice with targeted alpha emitting 227Th-DOTA-p-benzyl-trastuzumab. PLoS One. 2012;7(8):e42345. 
8. Scott AM, Mitchell PL, O'Keefe G, et al. Pharmacodynamic analysis of tumour perfusion assessed by $15 \mathrm{O}$-water-PET imaging during treatment with sunitinib malate in patients with advanced malignancies. EJNMMI Res. 2012;2(31):1-21.

9. Rutkowski P, Bylina E, Klimczak A, et al. The outcome and predictive factors of sunitinib therapy in advanced gastrointestinal stromal tumors (GIST) after imatinib failure - one institution study. BMC Cancer. 2012;12:107.

10. Delbaldo C, Faivre S, Dreyer C, Raymond E. Sunitinib in advanced pancreatic neuroendocrine tumors: latest evidence and clinical potential. Ther Adv Med Oncol. 2012;4(1):9-18.

11. Watanabe K, Otsu S, Morinaga R, et al. Vesicocutaneous fistula formation during treatment with sunitinib malate: case report. $B M C$ Gastroenterol. 2010;10:128.

12. Kodera Y, Katanasaka Y, Kitamura Y, et al. Sunitinib inhibits lymphatic endothelial cell functions and lymph node metastasis in a breast cancer model through inhibition of vascular endothelial growth factor receptor 3 . Breast Cancer Res. 2011;13(3):R66.

13. Ballas MS, Chachoua A. Rationale for targeting VEGF, FGF, and PDGF for the treatment of NSCLC. Onco Targets Ther. 2011;4:43-58.

14. Pal SK, Figlin RA, Yu H. Deciphering the anticancer mechanisms of sunitinib. Cancer Biol Ther. 2010;10(7):712-714.

15. Poon RT, Fan ST, Wong J. Clinical implications of circulating angiogenic factors in cancer patients. J Clin Oncol. 2001;19(4): 1207-1225.

16. Duda DG, Jain RK, Willett CG, et al. Antiangiogenics: the potential role of integrating this novel treatment modality with chemoradiation for solid cancers. J Clin Oncol. 2007;(25):4033-4042.

17. Chen YY, Yeh CN, Cheng CT, et al. Sunitinib for Taiwanese patients with gastrointestinal stromal tumor after imatinib treatment failure or intolerance. World J Gastroenterol. 2011;17(16):2113-2119.

18. Heinrich MC, Blanke CD, Druker BJ, Corless CL. Inhibition of KIT tyrosine kinase activity: a novel molecular approach to the treatment of KIT-positive malignancies. J Clin Oncol. 2002;20(6): 1692-1703.

19. Kacinski BM. CSF-1 and its receptor in ovarian, endometrial and breast cancer. Ann Med. 1995;27(1):79-85.

20. Ferguson T, Gore M. Which patients with renal cancer may benefit from sunitinib therapy? Ther Adv Med Oncol. 2010;2(2):69-74

21. Hong MH, Kim HS, Kim C, et al. Treatment outcomes of sunitinib treatment in advanced renal cell carcinoma patients: a single cancer center experience in Korea. Cancer Res Treat. 2009;41(2):67-72.

22. Zama IN, Hutson TE, Elson P, et al. Sunitinib rechallenge in metastatic renal cell carcinoma patients. Cancer. 2010;116(23): $5400-5406$

23. Motzer RJ, Hutson TE, Tomczak P, et al. Sunitinib versus interferon alfa in metastatic renal-cell carcinoma. $N$ Engl J Med. 2007;356(2): $115-124$.

24. Cella D, Michaelson MD, Bushmakin AG, et al. Health-related quality of life in patients with metastatic renal cell carcinoma treated with sunitinib vs interferon-a in a phase III trial: final results and geographical analysis. Br J Cancer. 2010;102(4):658-664.

25. Blagoev KB, Wilkerson J, Stein WD, Motzer RJ, Bates SE, Fojo AT. Effect of sunitinib (SU) administration on post-treatment survival in patients with metastatic renal cell carcinoma (mRCC) treated on the upfront randomized phase III trial of sunitinib or interferon alfa (IFN). J Clin Oncol. 2011;29 Suppl:4634.

26. Keizman D, Huang P, Eisenberger MA, et al. Angiotensin system inhibitors and outcome of sunitinib treatment in patients with metastatic renal cell carcinoma: a retrospective examination. Eur J Cancer. 2011;47(13): 1955-1961.

27. Molina AM, Feldman DR, Ginsberg MS, et al. Phase II trial of sunitinib in patients with metastatic non-clear cell renal cell carcinoma. Invest New Drugs. 2012;30(1):335-340.

28. Rini BI, Cohen DP, Lu DR, et al. Hypertension as a biomarker of efficacy in patients with metastatic renal cell carcinoma treated with sunitinib. J Natl Cancer Inst. 2011;103(9):763-773.
29. van der Veldt AA, Meijerink MR, van den Eertwegh AJ, Haanen JB, Boven E. Choi response criteria for early prediction of clinical outcome in patients with metastatic renal cell cancer treated with sunitinib. Br J Cancer. 2010;102(5):803-809.

30. Yoo C, Kim JE, Lee JL, et al. The efficacy and safety of sunitinib in Korean patients with advanced renal cell carcinoma: high incidence of toxicity leads to frequent dose reduction. Jpn J Clin Oncol. 2010;40(10): 980-985.

31. Molina AM, Feldman DR, Voss MH, et al. Phase 1 trial of everolimus plus sunitinib in patients with metastatic renal cell carcinoma. Cancer. 2012;118(7):1868-1876.

32. Keizman D, Ish-Shalom M, Pili R, et al. Bisphosphonates combined with sunitinib may improve the response rate, progression free survival and overall survival of patients with bone metastases from renal cell carcinoma. Eur J Cancer. 2012;48(7):1031-1037.

33. Tielen R, Verhoef C, van Coevorden F, et al. Surgery after treatment with imatinib and/or sunitinib in patients with metastasized gastrointestinal stromal tumors: is it worthwhile? World J Surg Oncol. 2012;10:111.

34. Kapoor R, Khosla D, Kumar P, Kumar N, Bera A. Successful treatment with sunitinib in a young patient with metastatic gastrointestinal stromal tumor after failure on adjuvant imatinib. J Cancer Res Ther. 2011;7(4): 491-493.

35. Henze J, Mühlenberg T, Simon S, et al. p53 Modulation as a therapeutic strategy in gastrointestinal stromal tumors. PLoS One. 2012;7(5):e37776.

36. Italiano A, Cioffi A, Coco P, et al. Patterns of care, prognosis, and survival of patients with metastatic gastrointestinal stromal tumors (GIST) refractory to first-line imatinib and second-line sunitinib. Ann Surg Oncol. 2012;19(5):1551-1559.

37. Bertucci F, Ray-Coquard IL, Nguyen BB, et al. Effect of five years of imatinib on cure for patients with advanced GIST: updated survival results from the prospective randomized phase III BFR14 trial. $J$ Clin Oncol. 2012;30 Suppl:10095.

38. Matsumoto K, Sawaki A, Mizuno N, et al. Clinical efficacy and safety of sunitinib after imatinib failure in Japanese patients with gastrointestinal stromal tumor. Jpn J Clin Oncol. 2011;41(1):57-62.

39. Rapiti E, Verkooijen HM, Vlastos G, et al. Complete excision of primary breast tumor improves survival of patients with metastatic breast cancer at diagnosis. J Clin Oncol. 2006;24(18):2743-2749.

40. Nielsen DL, Andersson M, Andersen JL, Kamby C. Antiangiogenic therapy for breast cancer. Breast Cancer Res. 2010;12(5):209.

41. Curigliano G, Pivot X, Cortés J, et al. Randomized phase II study of sunitinib versus standard of care for patients with previously treated advanced triple-negative breast cancer. Breast. 2013;22(5):650-656.

42. Knox JJ, Wong R, Darling GE, et al. Adjuvant sunitinib ( $\mathrm{Su}$ ) for locally advanced esophageal cancer (LAEC): results of a phase II trial. J Clin Oncol. 2011;29 Suppl:4091.

43. Jo JC, Hong YS, Kim KP, et al. A prospective multicenter phase II study of sunitinib in patients with advanced aggressive fibromatosis. J Clin Oncol. 2013;31 Suppl:10589.

44. Cheng A, Kang Y, Lin D, et al. Phase III trial of sunitinib (Su) versus sorafenib (So) in advanced hepatocellular carcinoma (HCC). J Clin Oncol. 2011;29 Suppl:4000.

45. Yau TC. Efficacy and safety of single-agent sunitinib in treating patients with advanced hepatocellular carcinoma after sorafenib failure: a prospective, open-label, phase II study. J Clin Oncol. 2011; 29 Suppl:4082.

46. Antonelli A, Fallahi P, Ferrari SM, et al. New targeted therapies for thyroid cancer. Curr Genomics. 2011;12(8):626-631.

47. Pasqualetti G, Ricci S, Boni G, et al. Off-label use of sunitinib in patients with advanced, epithelial thyroid cancer: a retrospective analysis. Recent Pat Endocr Metab Immune Drug Discov. 2012;6(2):171-176.

48. Carr LL, Mankoff DA, Goulart BH, et al. Phase II study of daily sunitinib in FDG-PET-positive, iodine-refractory differentiated thyroid cancer and metastatic medullary carcinoma of the thyroid with functional imaging correlation. Clin Cancer Res. 2010;16(21):5260-5268. 
49. O’Neill PA, Butt M, Eswar CV, Gillis P, Marshall E. A prospective single arm phase II study of dacarbazine and treosulfan as first-line therapy in metastatic uveal melanoma. Melanoma Res. 2006;16(3):245-248.

50. Sacco JJ, Nathan PD, Danson S, et al. Sunitinib versus dacarbazine as first-line treatment in patients with metastatic uveal melanoma. J Clin Oncol. 2013;31 Suppl:S9031.

51. Reynolds C, Spira AI, Gluck L, et al. Sunitinib malate in previously untreated, nonsquamous, non-small cell lung cancer patients over the age of 70 years: results of a Phase II trial. Invest New Drugs. 2013;31(5): $1330-1338$.

52. Heist RC, Wang XF, Hodgson L, et al. A randomized phase II study to assess the efficacy of pemetrexed or sunitinib or pemetrexed plus sunitinib in the second-line treatment of advanced non-small cell lung cancer (NSCLC). J Clin Oncol. 2012;30 Suppl:7513.

53. Han J, Lim KY, Kim HY, et al. Phase II study of sunitinib in patients with relapsed or refractory small cell lung cancer (SCLC). Lung Cancer. 2013;73(2):137-142.

54. Raymond E, Niccoli P, Raoul J, et al. Updated overall survival (OS) and progression-free survival (PFS) by blinded independent central review (BICR) of sunitinib (SU) versus placebo (PBO) for patients (Pts) with advanced unresectable pancreatic neuroendocrine tumors (NET). J Clin Oncol. 2011;29 Suppl 4:249

55. Ketola K, Kallioniemi O, Iljin K. Chemical biology drug sensitivity screen identifies sunitinib as synergistic agent with disulfiram in prostate cancer cells. PLoS One 2012;7(12):e51470.

56. Michaelson MD, Sengeløv L, Saad F, et al. Randomized, placebocontrolled, phase III trial of sunitinib in combination with prednisone (SU P) versus prednisone $(\mathrm{P})$ alone in men with progressive metastatic castration-resistant prostate cancer (mCRPC). J Clin Oncol. 2011 29 Suppl:4515.

57. Lee KW, Park SR, Oh DY, et al. Phase I study of sunitinib plus capecitabine/cisplatin or capecitabine/oxaliplatin in advanced gastric cancer. Invest New Drugs. 2013;31(6):1547-1558.

58. Robert NJ, Saleh MN, Paul D, et al. Sunitinib plus paclitaxel versus bevacizumab plus paclitaxel for first-line treatment of patients with advanced breast cancer: a phase III, randomized, open-label trial. Clin Breast Cancer. 2011;11(2):82-92.

59. Moehler MH, Thuss-Patience PC, Schmoll HJ, et al. FOLFIRI plus sunitinib versus FOLFIRI alone in advanced chemorefractory esophagogastric cancer patients: a randomized placebo-controlled multicentric AIO phase II trial [abstract]. J Clin Oncol. 2013;31 Suppl:4086.

60. Schmitt JM, Sommers SR, Fisher W, et al. Sunitinib plus paclitaxel in patients with advanced esophageal cancer: a phase II study from the Hoosier Oncology Group. J Thorac Oncol. 2012;7(4):760-763.

61. Richly H, Maute L, Heil G, et al. Prospective randomized phase 2II trial with gemcitabine versus gemcitabine plus sunitinib in advanced pancreatic cancer: a study of the CESAR Central European Society for Anticancer Drug Research-EWIV. J Clin Oncol. 2013;31 Suppl: 4035.

62. Lankheet NA, Kloth JS, Gadellaa-van Hooijdonk CG, et al. Individual PK-guided sunitinib dosing: a feasibility study in patients with advanced solid tumors. J Clin Oncol. 2012;30 Suppl:2596.

63. Duerinck J, Du Four S, Van Binst A, et al. Phase II trial of sunitinib malate and lomustine in patients with temozolomide refractory recurrent low-grade and anaplastic gliomas. J Clin Oncol. 2012;30 Suppl: 2050 .

64. Laurie SA, Gupta A, Chu Q, et al. Brief report: a phase II study of sunitinib in malignant pleural mesothelioma. The NCIC Clinical Trials Group. J Thorac Oncol. 2011;6(11):1950-1954.

65. Galsky MD, Hahn NM, Powles T, et al. Gemcitabine, cisplatin, and sunitinib for metastatic urothelial carcinoma and as preoperative therapy for muscle-invasive bladder cancer. Clin Genitourin Cancer. 2013;11(2):175-181.

66. Ready N, Pang H, Gu L, et al. Chemotherapy with or without maintenance sunitinib for untreated extensive-stage small cell lung cancer: a randomized, placebo controlled phase II study CALGB 30504 (ALLIANCE). J Clin Oncol. 2013;31 Suppl:S750.
67. Dallas J, Imanirad I, Rajani R, et al. Response to sunitinib in combination with proton beam radiation in a patient with chondrosarcoma: a case report. J Med Case Rep. 2012;6:41.

68. Kao J, Chen CT, Tong CC, et al. Concurrent sunitinib and stereotactic body radiotherapy for patients with oligometastases: final report of a prospective clinical trial. Target Oncol. Epub May 10, 2013.

69. Sun J, Sun QH, Brown MF, et al. The multi-targeted kinase inhibitor sunitinib induces apoptosis in colon cancer cells via PUMA. PLoS One. 2012;7(8):e43158.

70. Ellis LM, Hicklin DJ. VEGF-targeted therapy: mechanisms of antitumour activity. Nat Rev Cancer. 2008;8(8):579-591.

71. Marshall E, Coupland S, Corrie P, et al. A randomized phase II study of sunitinib versus dacarbazine in the treatment of patients with metastatic uveal melanoma. J Clin Oncol. 2012;30 Suppl:TPS8605.

72. Armstrong AJ, Halabi S, Eisen T, et al. ASPEN: a randomized phase II trial of everolimus versus sunitinib in patients with metastatic non-clear cell renal cell carcinoma. J Clin Oncol. 2013;31 Suppl:TPS4590.

73. Huang D, Ding Y, Zhou M, et al. Interleukin-8 mediates resistance to antiangiogenic agent sunitinib in renal cell carcinoma. Cancer Res. 2010;70(3):1063-1071.

74. Shojaei F, Lee JH, Simmons BH, et al. HGF/c-Met acts as an alternative angiogenic pathway in sunitinib-resistant tumors. Cancer Res. 2010;70(24):10090-10100.

75. Thodima VJ, Molina AM, Jia X, et al. Molecular classification of sunitinib response in metastatic renal cell carcinoma ( $\mathrm{mRCC}$ ) patients by gene expression profiling. J Clin Oncol. 2011;29 Suppl:4556.

76. Sato M, Nakai Y, Nakata W, et al. EMMPRIN promotes angiogenesis, proliferation, invasion and resistance to sunitinib in renal cell carcinoma, and its level predicts patient outcome. PLoS One. 2013;8(9):e74313.

77. Di Fiore F, Rigal O, Menager C, Michel P, Pfister C. Severe clinical toxicities are correlated with survival in patients with advanced renal cell carcinoma treated with sunitinib and sorafenib. Br J Cancer. 2011;105(12):1811-1813.

78. Schwandt A, Wood LS, Rini B, Dreicer R. Management of side effects associated with sunitinib therapy for patients with renal cell carcinoma. Onco Targets Ther. 2009;2:51-61.

79. Charbonneau C, Sandin R. Comment on 'costs of managing adverse events in the treatment of first-line metastatic renal cell carcinoma: bevacizumab in combination with interferon- $\alpha 2$ a compared with sunitinib'. $\mathrm{Br} J$ Cancer. 2010;103(8):1307-1308; author reply 1309-1310.

80. Kim HS, Hong MH, Kim K, et al. Sunitinib for Asian patients with advanced renal cell carcinoma: a comparable efficacy with different toxicity profiles. Oncology. 2011;80(5-6):395-405.

81. Sato S, Muraishi K, Tani J, et al. Clinical characteristics of thyroid abnormalities induced by sunitinib treatment in Japanese patients with renal cell carcinoma. Endocr J. 2010;57(10):873-880.

82. Cho DC. Prognostic biomarkers for patients with advanced renal cell carcinoma treated with VEGF-targeted tyrosine kinase inhibitors. Onco Targets Ther. 2013;6:679-684.

83. Hillman GG, Singh-Gupta V, Al-Bashir AK, et al. Dynamic contrastenhanced magnetic resonance imaging of sunitinib-induced vascular changes to schedule chemotherapy in renal cell carcinoma xenograft tumors. Transl Oncol. 2010;3(5):293-306.

84. Huang D, Ding Y, Li Y, et al. Sunitinib acts primarily on tumor endothelium rather than tumor cells to inhibit the growth of renal cell carcinoma. Cancer Res. 2010;70(3):1053-1062.

85. Arbab AS. Activation of alternative pathways of angiogenesis and involvement of stem cells following anti-angiogenesis treatment in glioma. Histol Histopathol. 2012;27(5):549-557.

86. Harmon CS, DePrimo SE, Raymond E, et al. Mechanism-related circulating proteins as biomarkers for clinical outcome in patients with unresectable hepatocellular carcinoma receiving sunitinib. J Transl Med. 2011;9:120.

87. Fuchs K, Bize PE, Dormond O, et al. Drug-eluting beads loaded with antiangiogenic agents for chemoembolization: in vitro sunitinib loading and release and in vivo pharmacokinetics in an animal model. J Vasc Interv Radiol. 2014;25(3):379-387. e2. 
88. Walter S, Weinschenk T, Reinhardt C, Singh-Jasuja H. Single-dose cyclophosphamide synergizes with immune responses to the renal cell cancer vaccine IMA901. Oncoimmunology. 2013;2(1):e22246.

89. Hillman GG, Singh-Gupta V, Al-Bashir AK, et al. Monitoring sunitinibinduced vascular effects to optimize radiotherapy combined with soy isoflavones in murine xenograft tumor. Transl Oncol. 2011;4(2): $110-121$.
90. Flaig TW, Costa LJ, Gustafson DL, et al. Safety and efficacy of the combination of erlotinib and sirolimus for the treatment of metastatic renal cell carcinoma after failure of sunitinib or sorafenib. Br J Cancer. 2010;103(6):796-801.

\section{Publish your work in this journal}

OncoTargets and Therapy is an international, peer-reviewed, open access journal focusing on the pathological basis of all cancers, potential targets for therapy and treatment protocols employed to improve the management of cancer patients. The journal also focuses on the impact of management programs and new therapeutic agents and protocols on

\section{Dovepress}

patient perspectives such as quality of life, adherence and satisfaction. The manuscript management system is completely online and includes a very quick and fair peer-review system, which is all easy to use. Visit http://www.dovepress.com/testimonials.php to read real quotes from published authors.

\footnotetext{
Submit your manuscript here: http://www.dovepress.com/oncotargets-and-therapy-journal
} 